\title{
The Use of Supplemental Instruction in University Classrooms as a Strategy to Enhance the Academic Performance of First-year Students
}

\author{
Oyinlola Omolara Adebola \\ School of Social Sciences and Language Education, Faculty of Education, University of the Free State, Republic of South Africa
}

Received June 23, 2020; Revised August 15, 2020; Accepted October 19, 2020

\section{Cite This Paper in the following Citation Styles}

(a): [1] Oyinlola Omolara Adebola, "The Use of Supplemental Instruction in University Classrooms as a Strategy to Enhance the Academic Performance of First-year Students, "Universal Journal of Educational Research, Vol. 8, No. 11B, pp. 6289-6296, 2020. DOI: 10.13189/ujer.2020.082268.

(b): Oyinlola Omolara Adebola (2020). The Use of Supplemental Instruction in University Classrooms as a Strategy to Enhance the Academic Performance of First-year Students. Universal Journal of Educational Research, 8(11B), 6289-6296. DOI: 10.13189/ujer.2020.082268.

Copyright $\bigcirc 2020$ by authors, all rights reserved. Authors agree that this article remains permanently open access under the terms of the Creative Commons Attribution License 4.0 International License

\begin{abstract}
This study explores the use of supplemental instruction (SI), a type of academic support, to enhance the performance of first-year students in universities. This study, therefore, questions the challenges associated with the use of supplemental instruction in a university and the possible solutions. Social constructivism (SC) as a theoretical framework was adopted while Participatory Research (PR) was used because of its assumption that the coming together of the concerned people in the study would give them a sense of belonging, participation in problem definition, problem assessment, implementation and evaluation. Unstructured interviews were used to collect data. The participants of the study include two first-year students, two SI coordinators, two tutors and two lecturers from the selected university. Thematic Analysis (TA) was adopted to analyse, interpret and describe the generated data; as a result its involvement in the reflected categorised objectives. The study concluded that challenges, such as the gap in communication, that is, lack of effective communication and over enrolment were the major problems confronting the implementation of SI while up-to-date evaluation and feedback and provision of educational facilities were the solutions suggested to overcome these problems.
\end{abstract}

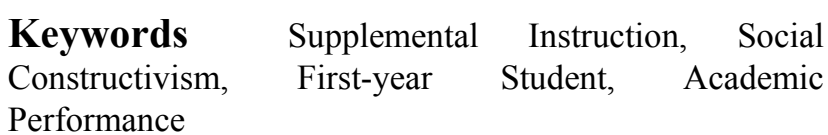

\section{Introduction}

Higher education, according to Alemu (2018), is an umbrella for all institutional teaching and learning, such as the university where a degree is issued at the end of specific years according to the university rules. This is also echoed by Irene and Forbes (2008) that a university is an institution where teaching and learning experiences take place and that these experiences are co-created among students, students and lecturers and students and administrators. However, in South Africa education system and other parts of the world, so many factors such as inadequate planning, ineffective communication among the stakeholders, lack of interaction between students and lecturers and inadequate academic support from universities have been mentioned as some of the problems responsible for the low academic performance of students according to the findings of Kenya Education Sector Support Programme (KESSA 2005; Mukhanji, Ndiku \& Obasi, 2016). This is to say that with this kind of problem, students' academic performance could be hindered due to the large number of students enrolled in different courses at universities. It is in light of these problems that this research used the SI intervention. Other problems, such as lack of interaction between student and lecturer, could be 
ameliorated because SI works in such a way that students are divided in a smaller group where every student is given attention (Ribera, BrckaLorenz, \& Ribera, 2012). Therefore, this study assisted selected university students who had these academic challenges by using supplemental instruction as academic support.

Researchers such as Etter, Sandra, Burmeisterand Elder (2001) investigated and found out that students who attended SI section performed better in terms of overall first-year credit than students who did not attend SI sessions. Meanwhile, Joakim, Leif and Lise (2012) mentioned that students with low, average and high prior academic achievements all benefitted from attending SI sessions. This is to say, supplemental instruction enhances the academic performance of the students that attend tutorials compared to those who do not which necessitated this study. Supplemental Instruction is academic support rendered by the university to assist students who have difficulties in passing specific modules, to assist classes with a large number of students and also, to boost the academic performance of students (Naidoo \& Paideya, 2015). Supplemental Instruction in the context of this study refers to the academic support system rendered by a university through tutors to help students improve academically, especially in some specific modules (Philip, Jacques, Jane \& Kym, 2014). Schultz (2017) defined SI as a model that is fashioned to assist students in historically difficult content and study strategically through peer-led discussion style. Furthermore, Johnson and Lozada (2018) stated that "SI is a free, peer-facilitated academic assistance programme developed with the overall goal of identifying and supporting the most challenging courses. SI sessions are regularly-scheduled, informal review sessions that involve collaborative learning activities through which students can clarify course concepts and practise the types of study strategies that will help them truly master the information and skills required by the target course". This definition by Johnson and Lozada (2018) attests to the benefits inherent in SI as a strategy to support first-year students.

This study bridged the gap by providing academic assistance in the form of Supplemental Instruction for those students who are performing poorly at universities. This kind of academic support works in a way that the senior students who have passed the specific modules are employed by the university to tutor the junior students (Joakim et al., 2012). From the above, a rhetorical question exists that if SI is such successful academic support as claimed above, then why do students who receive this kind of support still perform below average. In the selected university, tutorial sessions which are also known as supplemental instruction have been in existence for a long period (2015-2019) of time especially for first-year students. This assistance is rendered for students who have difficulty in some modules or large classes that have more than 1000 students.

\subsection{Problem Statement}

The researcher, who was once a tutor with a large class of almost 1200 students in the particular module being offered by the first-year students, happened to observe and experienced these issues. The researcher discovered that student's marks were below-average grades in the module under investigation. To the researcher, this is a problem that needs to be investigated as to know why students perform below average despite the SI involvement. Mouton, Louw and Strydom (2013) revealed that some of the factors that led to poor academic performance were drop-out, underperforming lecturers and lack of support from the community, the community in this sense is referred to as the university. This means that poor academic performance is a huge problem in universities. In my argument and experience, the intervention of SI could enhance students' performance. This was mentioned in the conclusion of Adebola, Tsotetsi and Omodan (2020) that the intervention of SI is significant to high pass rate and students' performance in the university system. This study, therefore, becomes expedient because the rate at which students drop out of universities nowadays is alarming and has been linked to factors such as lack of support, availability of resources, overcrowded classrooms and over enrolment (Kapur, 2018). These and many more seem to have negatively affected student academic productivity, and therefore urgent attention is called for.

\subsection{Theoretical Framework}

Social Constructivism (SC) as a theory was used for this study. SC was founded by (Vygotsky (1978) on the premises that the construction of knowledge is not limited to the classroom alone but exist outside school buildings (Kim, 2001). This theory posited that collaborative learning, group learning and many other forms of learning style can be incorporated to aid students learning. Students can learn while socialising with their peers either within or outside the classroom and knowledge is constructed in a meaningful way (Dagar \& Yadav, 2016). Meanwhile, it is assumed that constructivism has multiple ontologies that can be traceable to cognitivism psychology and philosophy. This means that while learning, students do make use of their cognitive skills in such a way that they process, store and bring out information as at when due. Therefore, learning in a social context according to SC helps students to construct their meaning while the tutor facilitates, and not instead of instructing (Bada, 2015; Ardiansyah \& Ujihanti, 2018:6).

Since this study focuses on enhancing the academic performance of the first-year students in universities using supplemental instruction, Social Constructivism (SC) as a theoretical framework becomes relevant because both share similar underlying assumption on how best students learn in a group. SC stresses the importance of collaborative learning and contextual learning. This is to 
say that both SI and SC emphasise that how and where students learn is an important criterion in enhancing academic performance. One of the roles of tutors is to give attention to students who are divided into smaller groups for knowledge construction. (Bada, 2015). SC believes that learning should be seen as a building block whereby students build knowledge on the previous information acquired. Meanwhile, the major role of a tutor in this study is to facilitate learning to ensure that students get clarification regarding the subject matter. This means that learning is a process whereby students are incorporated into the knowledge culture through social negotiations by tutors. With these, it is believed that with the assistance of tutors, the academic performance of first-year students will be enhanced through the use of Supplemental Instruction in universities if implemented since that was the aim of the study. Apart from enhancing academic performance, research shows that through SI intervention, the principle of allowing students to share knowledge collaboratively and the inclusion of diverse learning in a social context has led to lower dropout rate, retention rate and increase in the graduation rate (Chambers-Turner, 2010).

\section{Research Question}

Based on the background presented in this study, this research question was answered:

- How can Supplemental Instruction be used as a strategy to enhance the academic performance of first-year students in universities?

\section{Research Objectives}

The following research objectives will also pilot the study. That is, the study:

- Examined the challenges facing the use of SI to enhance student academic performance in the universities.

- Investigated possible solutions to the academic challenges encountered by first-year students in order to ensure that they are supported during their academic programme.

\section{Methodology}

\subsection{Research Design}

Participatory research (PR) was chosen for this study as the research design due to the nature of how the research was conducted. Participatory research is grounded on the assumption that the voice of the concerned people must be heard (Jard \& Thomas, 2012). Participatory research is a type of research that believes that both researcher and the participants should work together to empower the concerned from being marginalised. This is why (Reason \& Bradbury, 2008) conceptualised PR as a process that involves the coming together of both and brings about a new insight into the part of both the researcher and co-researchers, theory and practice in collaboration with the concerned community members in the process of generating knowledge and solution to the issue that is bothering them. This means that people that are faced with the problem under this study were also part of the process to find solutions to the problem. The above definitions also show that PR enables people facing the problem to be regarded as co-researchers who are involved in the development of knowledge to better their lives and community. PR aims to investigate and explore the concerned people from their perspective experiences and to proffer solutions (Williamson, 2018). However, PR allows the concerned to express their views regarding a particular topic that have been a burden to them. This opportunity gives them a sense of belonging and ownership. From the above, it is therefore confirmed that knowledge under PR is generated through a social and collaborative relationship which could be regarded as the epistemology of PR (Heron \& Reason, 2001). For this reason, PR is deemed fit for this study because it collaborates with the concerned people; bringing both participants and researcher together to give solutions to the challenges facing the implementation of supplemental instruction in a university.

\subsection{Method of Data Collection}

An unstructured interview which is also known as "in-depth interview" was used to collect data in this study. An unstructured interview is a type of interview that does not have a specific standard of predetermined questions, even though the researcher normally have certain topics of interest during the informal and open-ended conversation (Dana, Dawes \& Peterson, 2012). This specific method was used because the researcher wanted to investigate a particular topic since according to Dana (2015), it was suggested that unstructured interview is the best method to use in this regard. The data collection process was democratic in nature, that is, the participants have the right to withdraw at any time if they feel otherwise. The researcher had a meeting with the participants which was aimed at clarifying the purpose of the unstructured interviews. Boyden, Ennew and Judith (2012) stated that because of the democratic nature of this method, participants should be treated equally, the process should be transparent and the participant should be involved in the decision-making. The interview was focused on challenges and solutions confronting first-year students. After the generation of data, the researcher presented the report to co-researchers to check, add inputs and suggest corrections. 


\subsection{Participants' Selection}

In this study, eight participants were selected; two were first-year students offering the particular module, two lecturers who taught the module, two tutors and two supplemental instruction (SI) leaders who were responsible for the administrative tasks. The reasons for this selection was that two students who attended a tutorial session of the module under investigation are to share the challenges they experienced regarding supplemental instruction, the lecturers are to share their experiences towards the module, the tutors will share the challenges they face during tutorial sessions and the SI leaders who are to assist the researcher with the challenges will share what they encountered during SI. The participants were regarded as co-researchers and at some point may also be regarded as the co-participants for the study. Their characteristics are also exposed to justify the reasons for selecting them. Meanwhile, the selection of the participants bordered on the sampling techniques used in selecting the participants. The appropriateness of the participants' selection techniques is also dealt with.

\subsection{Method of Data Analysis and Ethical Consideration}

To analyse the data collected for this study, Thematic Analysis (TA) was used. Thematic analysis is a process used in all qualitative analysis to assist researchers in analysing their data based on themes and sub-themes (Holloway \& Todres, 2003). TA is a type of analysis that provides the researcher with the opportunity to identify, compare and determine the data found within the data set (Ibrahim, 2012). While Braun and Clarke (2006) said that TA makes data analysis easy and easily understood especially when summarising critical concepts of a large amount of data. Ethical consideration for the study was approved by the ethical committee of the University of the Free State with approval number UFS-HSD2018/1132. The consent of the participants was sought, and they were provided with information that, during, and after the study, their information and utterances will be kept confidential from third-party. They were assured that their names would not be disclosed to a third-party and that their responses would remain anonymous.

\section{Presentation of Data}

To enhance the academic performance of first-year students in a university with the use of SI, below are some of the challenges and solutions that were found during the course of the study; the gap in communication and over enrolment was found to be the challenges, while the provision of educational facilities and up-to-date evaluation were found to be the solutions. For anonymity, the participants were represented using A1 \& A2
(Lecturers), B1 \& B2 (Tutees), $\mathrm{C} 1 \& \mathrm{C} 2$ (Tutors), and D1 $\&$ D2 (SI Leaders).

\subsection{Challenges with the use of SI to Enhance Academic Performance}

\subsubsection{Gap in Communication}

Effective communication is the most important factor in the teaching and learning process; without it, SI is meaningless. This is another challenge that hinders the implementation of supplemental instruction in universities and other institutions of learning. When communication is not clear, students, especially those who are in the first year and just find their way into the university environment, are lost and do not know what to do concerning a particular instruction. In a supplemental instruction, communication among all the stakeholders involved is very vital, and this includes: tutors, students (tutees), lecturers and SI leaders (coordinators). Meanwhile, a lecturer is supposed to brief tutors on what they must teach in the class and at the same time, the tutor ought to give feedback to the lecturer and SI coordinators. This channel of communication keeps SI personnel abreast of what is happening at tutorial sessions and informs them of the next action or strategy to take in order to improve the support. Participants also agreed that the lack of communication and relationship among collaborators hinder the success of SI, which makes it a challenge to support the argument that when communication during tutorials seems unclear, students stop attending and have a negative attitude towards SI (Moleko et al., 2014:742). Below are the comments from participants:

\section{Participant D2: "There is no proper communication between these parties such that most students miss their tutorials." \\ Participant A: "Communication between the lecturers and tutors has been lacking and can also be a challenge that will really require a way in which it is coordinated better"}

Proper communication among all the stakeholders also featured as a challenge facing the implementation of SI. It is not that there is no communication, but it is either the channel of communication is wrong or there is no effective communication. Participant D2 said that improper communication between students and tutors was the reason why students who attend tutorials miss classes. The same problem was echoed by participant A2 that the lack of or improper communication could be as a result of a lack of coordinated communication. That is, there is no proper communication. Participant A2 went further to say that apart from the issue of rapport between them; it was also reported that lack of communication is another challenge.

\subsubsection{Overenrolment}

Over enrolment in South African universities is another challenge facing the implementation of supplemental 
instruction. Over enrolment is when you have more people than expected in a university. Over enrolment has made it very difficult for higher institutions to accommodate applicants who wish to study in universities in South Africa The researcher believes that it is high time the government established more institutions of higher learning. For instance, the lecture rooms that were built years ago are not enough now because of a large number of students. Also, the library can only accommodate very few students.

Recently, in 2018 to be precise, there was an announcement from one of the influential political party leaders in South Africa that people who want to study could approach any university of their choices. Although this is a positive change that every higher institution should embrace, it does not make sense for a university to enrol more than its capacity due to the negative effects on staff members, students, management, output (graduates) and in the country at large. The over enrolment problem was supported by the statement made by the chancellor of the University of the Free State during one of his communication meeting with staff members that the campus has 5,000 students capacity, but because of over enrolment, it has a total number of 8,000 students. Below are the responses from the co-participants:

Participant A1: "The other challenge is the rate at which the QwaQwa campus grows, sometimes lecturers and tutors are unable to predict the number of students per tutor."

Participant C2: "Another challenge is lack of venue-large classes (a large number of students) and small venues."

In terms of over enrolment, participant A1's statement is supported by these statements and also observed in 2018 to be precise regarding over enrolment. Participant C2's statement also agreed with this. To address the other point raised, participant A1 said that campus growth is alarming and calls for urgent help from the government to create more universities to accommodate every would-be student. Although the university is located in a rural area and is a small campus compared to the main campus, the rate at which it is growing is high coupled with the challenge of over enrolment. Therefore, the resources cannot compete with the number of students on the campus. This sudden increment makes it difficult for lecturers, students and especially tutors to predict the number of students per tutor thus creating a challenge for SI. This argument is supported by Kausar, Kiyani and Suleman (2017) opinions that conductive environment contributes to effective teaching and learning; and unfortunately, over enrolment has been one of the major challenges in ensuring the implementation of SI in the university.

\subsection{Proffer solutions to the Challenges}

\subsubsection{Up-to-date Evaluation and Feedback}

Feedback and up-to-date evaluation are very good tools in determining how effective a particular strategy works, not excluding supplemental instruction. The essence of supplemental instruction is to assist students who experience challenges in some specific modules that require the university to support them through the use of tutors. Therefore, as much as the university provides the support, there is a need for constant evaluation and feedback from this support in order to ensure that not only is the support functioning but that students who need help are getting it and there is progress. Disha (2018) is in agreement that up-to-date evaluation and feedback could enhance first-year students' academic performance if all educational programmes including SI could be assessed and feedback received.

Participant A1: "The programme could face setback by irresponsible tutors. If you do not take action that on its own could be a threat to the programme because as a lecturer I am relying on them."

Participant D2: "Lecturers as well need to monitor them because if we do not monitor them, it can also create some gaps and some may capitalise on that."

From these statements, it is evident that up-to-date evaluation and feedback are a solution to the implementation of SI according to participant A1 and D2 emphasising the importance of monitoring and evaluation of tutors. For the implementation of SI to be a success, both lecturer and SI personnel need to follow up in monitoring and evaluating tutors to see if they are up to the task. It is possible that some tutors do not go to class during their tutorial sessions and still lay claims to what they do not deserve, but if there is monitoring and evaluating from time-to-time, students and tutors will be serious and know that if they fail to deliver, there is a penalty. Meanwhile, this will indirectly enhance the academic performance of first-year students and the implementation of SI as supported by Disha (2018).

Apart from monitoring and evaluation as a solution to SI, participant $\mathrm{C} 2$ raised the issue relating to regular communication among all the stakeholders of SI through workshop/training. This could be another avenue to get feedback and to evaluate tutors where all the stakeholders such as SI coordinators, lecturers, tutors and even students (tutees) hold a workshop in order to hear from everyone the challenges faced, proffer solutions and what they think could be the way forward in enhancing students' academic performance in the university. By doing this, tutors will be committed, be responsible and know that if they fail to carry out their responsibilities, there would be consequences. This will make the implementation of SI possible. Up-to-date feedback and evaluation could enhance the implementation of SI if there could be a platform where both students and tutor can lodge their problems/concerns.

\subsubsection{Provision of Educational Facilities}

For an organisation like the university to succeed, there 
must be adequate provision of educational facilities to some extent such as conducive lecture rooms, projectors, library and others. Omodan, Kolawole and Fakunle (2017) buttress that educational resources are required for the sustainability in teaching and learning activities. The implementation of SI will be hindered if all the necessary facilities are not available in any higher institution of learning especially in South African universities. Therefore, there is no doubt using SI to enhance the academic performance of first-year students in a university based on Oluwadare and Julius (2011) position that an adequately equipped environment enhances a conducive students/tutor interactions. Below are what the participants suggested to be conditions that will make the implementation of SI successful when generating data:

Participant B2: "Solution for the lecture halls with no air conditioners-if air conditioners can be installed so that students can come to class."

Participant B1: "The other condition is the issue of venues we need more as well as smaller venues that can accommodate students."

Participant C2: "Sometimes a tutor is prepared for the tutorial only to discover that there is no electricity. Even the Internet sometimes affects the smooth running of tutorials."

There are some issues such as venues without heater during winter and the interruption of electricity that are overlooked by university management as nothing serious. However, these could hinder the progress of students. From the statements made by Participant B2, it happens that some students stay away from tutorial sessions especially at the peak of winter (June/July). The suggestion here is that if the environment is conducive for learning, students will want to come to class. That is, the installation of heaters in lecture venues could be one of the solutions to the challenges facing the implementation of SI. Furthermore, for any university to succeed, there is a need for adequate educational facilities including lecture rooms/venues. Besides adequate educational facilities, another challenge encountered is of timetable clashes. The summary of participants B1, B2 and C2 are that no stone should be left unturned if the goal of any organisation and especially university has to be achieved; and therefore, conducive educational facilities are a necessity.

\section{Findings}

\subsection{Lack of Clear Communication as a Challenge}

Lack of clear communication was discovered during the data analysis process to be one of the challenges facing the implementation of SI. Clear communication is an aspect in academics that needs careful attention either horizontally or vertically if teaching and learning should be successful.
It emanated from the data that lack of clear communication between students and tutors, students and lecturers, SI personnel and tutors and even between SI personnel and lecturers are not effective. Research made it clear that due to lack of clear communication, students give reasons why tutorial sessions are not appealing to them and see no point of attending (Malm, Bryngfors \& Mörner, 2012). According to social constructivism theory, it is stated that one of the major factors that determine the success of peer learning is language, that is clear communication. Effective communication helps students to function well when interacting with other peers and even in the community (Gergen, 1995). Therefore, the findings show a contradictory phenomenon where the current reality indicates that there is a lack of clear communication among the SI personnel and students.

\subsection{Overenrolment as a Challenge}

It was found in this study that over enrolment due to challenges such as lack of venues for large classes and the rate at which the campus is growing has made SI implementation a problem. This is against what was alluded by Kausar, Kiyani and Suleman (2017) that conducive environment leads to effective learning and enhances the SI implementation. For effectiveness and implementation of SI, social constructivism believes that students learn better in a social setting and that knowledge should be constructed collaboratively among peers; otherwise students might not be comfortable to interact in an overcrowded classroom which could hinder the SI implementation (Ndiku, 2016).

\subsection{Up-to-date Evaluation and Feedback as a Solution}

Up-to-date evaluation and feedback, such as analysing and interpreting information on tutorials, were revealed to be one of the solutions that could make SI implementation a reality. This finding is held by Disha (2018) that evaluation and feedback enhance teaching and learning and that they help to make decisions concerning the programme. In this case, when there are up-to-date evaluation and feedback, SI as academic support could be evaluated if students are being enhanced or otherwise. With this practice, it will be easy for SI personnel to detect where to improve because there is always room for improvement. Up-to-date evaluation and feedback in SI involve all the stakeholders such as tutors, lecturers, tutees, SI coordinators and even the management to work together for the successful implementation of SI. This is to say that there should be quick feedback as soon as possible among themselves.

\subsection{Provision of Educational Facilities}

This study reveals that the provision of educational 
facilities such as conductive lecture rooms, projectors, library and others enhances performance. For instance, facilities like conducive lecture rooms are not negotiable in the university because students will have to gather in a venue for class and sit comfortably for teaching to be effective and meaningful. Even both tutor and lecturer are supposed to be able to walk around during this session, rather than staying in a spot because of a small venue for a large number of students. Omodan et al. (2017) talked about the benefits of having educational facilities in a university as it brings about effectiveness in teaching and learning. This study is not saying that there are no facilities in the university, but rather that they should be enough, working and be updated often. Provision of educational facilities is a condition which is necessary for the implementation of SI if provided.

\section{Conclusions}

The challenges facing the implementation of SI includes overcrowding as a result of over enrolment and institutional challenges such as a gap in communication. In that manner, the suggested solutions to these challenges remain communication and up-to-date evaluation and feedback. The study concludes that if the suggested solutions can be implemented, then SI implementation will be possible to enhance academic performance in a university. It also posits that if there could be effective communication among all the stakeholders, that is, lecturers, students and SI personnel then supplemental instruction will enhance the academic performance of first-year students if implemented in the university. Of course, the use of SI in a university as an academic supporting system is not a strange programme, but the aspect of using it to enhance first-year students' academic performance needs more attention of researchers. Therefore, the study urges universities to prioritise the implementation of SI in order to support the academic performance of first-year students. The study recommends that universities should prioritise communication among the stakeholders (tutors, lecturers, tutees) to boost first-year students' academic performance. Also, there should be constant feedback among the stakeholders, especially between lecturer and tutor. Therefore, it was mentioned that sometimes tutors do not know what to teach tutees due to the lack or delay in lecturers' response.

\section{REFERENCES}

[1] Adebola, O. Tsotetsi, C. \& Omodan, I. (2020). Enhancing students' academic performance in the university system: The perspective of supplemental instruction. International Journal of Learning, Teaching and Educational Research. 19(5), 217-230. https://doi.org/10.26803/ijlter.19.2.x
[2] Ardiansyah, W. \& Ujihanti, M. (2018). Social constructivism-based reading comprehension teaching design at Politeknik Negeri Sriwijaya. Arab World English Journal, 9(1), 9-16. https://dx.doi.org/10.24093/awej/vol9n o1.31

[3] Amineh, R. J. \& Asl, H.D. (2015). Review of constructivism and social constructivism. Journal of Social Sciences, Literature and Language, 9-16. http://blue-ap.org/j/List/4/is s/volume\%201\%20(2015)/issue\%2001/2.pdf

[4] Alemu, S, K. (2019). African higher education and the Bologna Process. European Journal of Higher Education, 9(1), 118-132, https://doi.org/10.1080/21568235.2018.1561 313

[5] Bada, \& Olusegun, S. (2015). Constructivism learning theory: A paradigm for teaching and learning, Journal of Research \& Method in Education, 5(6), 66-70. https://doi.org/10.9790/7388-05616670

[6] Braun, V. \& Clarke, V. (2006). Using thematic analysis in psychology. Qualitative Research in Psychology, 3(2), 77-101. https://doi.org/10.1191/1478088706063oA

[7] Dagar, V. \& Yadav, A. (2016). Constructivism: A paradigm for teaching and learning. .Arts and Social Sciences Journal, 2-4. https://doi.org/10.4172/2151-6200.1000200

[8] Disha, M. (2018). Evaluation in teaching and learning process.

http://www.yourarticlelibrary.com/statistics-2/evaluation-in -teaching-and-learning-process-education/92476

[9] Etter, E.R., Burmeister, S.L. \& Elder, R.J. (2000). Improving students' performance and retention via supplemental instruction. Journal of Accounting, 18(4), 355-368.

[10] Gergen, K.J., Steffe, L.P. \& Gale, J. (1995). Social construction and the educational process constructivism in education, 98(2), 50-54. Hillsdale: NJ Erlbaum.

[11] Ibrahim A. M. (2012). Thematic analysis: A critical review of its process and evaluation. West East Journal of Social Sciences,

https://fac.ksu.edu.sa/sites/default/files/ta_thematic_analysi s_dr_mohammed_alhojailan.pdf

[12] Irene, C. \& Forbes, J. (2008). Education as service: The understanding of university experience through the service logic. Journal of Marketing of Higher Education, 19(1), 2-26. https://core.ac.uk/download/pdf/12824514.pdf

[13] Jason, D., Robyn, M., Dawes, R. \& Peterson. (2012). Belief in the unstructured interview: The persistence of an illusion.https://www.sas.upenn.edu/ danajd/interview.pdf

[14] Joakim, M., Leif, B. \& Lise, M. (2012). Supplemental instruction improves grades but not persistence long-term impact. Journal of Developmental Education, 46(2), 2-8. http://dx.doi.org/10.1080/03075079.2010.535610

[15] Kausar, A., Kiyani, A. I. \& Suleman, Q. (2017). Effect of classroom environment on the academic achievement of secondary school students in the subject of Pakistan studies at secondary level in Rawalpindi District. Journal of Education and Practice, 8(24), 56-63.https://iiste.org/Journ als/index.php/JEP/article/view/38345/39421

[16] Kapur, R. (2018). Factors influencing the students' academic performance in secondary schools in India. Article. See 
discussions, stats, and author profiles for this publication at: https://www.researchgate.net/publication/324819919

[17] Lozada, N. \& Johnson, T. (2018). Bridging the supplemental instruction leader experience and post-graduation life. Learning Assistance Review, 23(1), 96-114.

[18] Ministry of Education Science and Technology. (2008). Kenya Education Sector Support Programme, 2005-2010. (KESSP).

[19] Mukhanji, J. M., Ndiku, M., J. \& Obasi, S. (2016). Effect of increased student enrolment on teaching and learning resources In Maseno University, Kenya. The International Journal of Social Sciences and Humanities Invention, 3( 3), 1938-1947. http://DOI:10.18535/ijsshi

[20] Malm, J., Bryngfors, L. \& Mörner, L. (2012). Supplemental instruction for improving first-year results in engineering studies. https://dx.doi.org/10.1080/03075079.2010.535610

[21] Moleko, M. M., Hlalele, D., \& Mahlomaholo, M. (2014). Challenges experienced with the implementation of supplemental instruction at institutions of higher education. Mediterranean Journal of Social Sciences, 5(27), 740-751.

[22] Malma, J., Bryngforsa, L. \& Mörner, L. (2014). The potential of supplemental instruction in engineering education: Helping new students to adjust to and succeed in university studies. European Journal of Engineering Education, 1-19. https://doi.org/10.1080/03043797.2014.96 7179

[23] Nelda, M., Louw, G.P. \& Strydom, G. (2013). Critical challenges of the South African school system. International Business \& Economics Research Journal, vol. 12. The Clute Institute http://www.cluteinstitute.com
[24] Naidoo, J. \& Vinodhani, P. (2015). Exploring the possibility of introducing supplemental instruction at secondary school level mathematics education, school of education. South African Journal of Education, http://dx.doi.org/10.15700/S AJE.V35N2A1022

[25] Omodan, B. I., Kolawole, A. O. \& Fakunle, F. A. (2016). School climate as correlates of teaching effectiveness of secondary school teachers in Osun State. International Journal of Educational Foundations and Management 10(1), 60-67.

[26] Oluwadare, O. I. \& Julius, O. (2011). Regional analysis of locations of public educational Facilities in Nigeria: The Akure region experience. Journal of Geography and Regional Planning, 4(7), 428-442.

[27] Piaget, J. \& Inhelder, B. (1969). The psychology of the child. New York: Basic Books.https://www.scirp.org/(S(351jmbn tvnsjtlaadkposzje))/reference/ReferencesPapers.aspx?Refer enceID $=2337032$

[28] Ribera, A. K., Brcka Lorenz, A. \& Ribera, T. (2012). Exploring the fringe benefits of supplemental instruction. 2-20.

http://cpr.indiana.edu/uploads/AIR\%202012\%20(SI\%20Fin al).pdf

[29] Rajendra, C. \& Sue, P. (2015). Challenges in higher education in South Africa. https://www.researchgate.net/pu blication/305213223

[30] Vygotsky, L.S. (1978). Tool and symbol in child development. The Development of Higher Psychological Processes. Harvard University Press, Cambridge. 